\title{
Assessing the Effects of Nitrogen Dioxide in Urban Air on Health of West and Southwest Cities of Iran
}

\author{
Elahe Zallaghi ${ }^{1,}$; Gholamreza Goudarzi ${ }^{2}$; Mehdi Nourzadeh Haddad ${ }^{3}$; Seyedeh Marzieh \\ Moosavian ${ }^{4}$; Mohammad Javad Mohammadi ${ }^{5}$ \\ ${ }_{1}^{1}$ Young Researchers and Elite Club, Khuzestan Science and Research Branch, Islamic Azad University, Ahvaz, IR Iran \\ ${ }_{3}^{2}$ Department of Environmental Health Engineering, School of Public Health, Ahvaz Jundishapur University of Medical Sciences, Ahvaz, IR Iran \\ ${ }^{3}$ Department of Agricultural, Payame Noor University, Tehran, IR Iran \\ ${ }_{5}^{4}$ Khuzestan Science and Research Branch, Islamic Azad University, Ahvaz, IR Iran \\ 5 Department of Environmental Technologies Research Center (ETRC), Ahvaz Jundishapur University of Medical Sciences, Ahvaz, IR Iran \\ ${ }^{*}$ Corresponding author: Elahe Zallaghi, Young Researchers and Elite Club, Khuzestan Science and Research Branch, Islamic Azad University, Ahvaz, IR Iran. Tel:+98-9361655938, E-mail: \\ elahe zallaghi@yahoo.com
}

Received: June 25, 2014; Revised: July 26, 2014; Accepted: July 27, 2014

\begin{abstract}
Background: Nitrogen dioxide $\left(\mathrm{NO}_{2}\right)$ is a corrosive, strong oxidant and a physiologic stimulant of lower respiratory tract. Every human being inhales an average of $10 \mathrm{~m}^{3}$ air per day; therefore, assessment of the effect of inhaled air on health is a vital issue. The main source $\mathrm{NO}_{2}$ in urban regions is intra-urban public transport system. The annual average of determined air quality for $\mathrm{NO}_{2}$ is $40 \mu \mathrm{g} / \mathrm{m}^{3}$.

Objectives: The present study aimed to estimate and compare epidemiologic indices attributed to the pollutant $\mathrm{NO}_{2}$ in the urban air of southwest cities of Iran, namely, Ahvaz, Kermanshah, and Bushehr, in 2011.

Materials and Methods: In the present study, data relevant to the air-pollutant $\mathrm{NO}_{2}$ in 2011 was obtained from the Iranian Department of Environment and meteorological organizations of the studied cities. Raw data processing by Excel software included instruction set correction of averaging, coding, and filtering. Then the meteorological parameters were converted as input file to the Air Q model. Finally, by using epidemiologic formulas, relative risk(RR) and attributed part to $\mathrm{NO}_{2}$ in the three studied cites were estimated.

Results: The results showed that in summer, winter, and the whole year, Kermanshah and Bushehr had on average the maximum and minimum $\mathrm{NO}_{2}$ concentration, respectively, in 2011. In addition, accumulative number of cases attributed to exposure with $\mathrm{NO}_{2}$ in the studied cities was maximum in Kermanshah (21 cases) and minimum in Bushehr (one case). The results revealed that approximately, the maximum number of death cases attributed to $\mathrm{NO}_{2}$ were observed in Kermanshah due to heart problems (1.06\%), acute infarction (1.8\%), and obstructive pulmonary disease (1.9\%) with concentration $>20 \mu \mathrm{g} / \mathrm{m}^{3}$.

Conclusions: Every $10 \mu \mathrm{g} / \mathrm{m}^{3}$ increase in the concentration of the pollutant $\mathrm{NO}_{2}$ in the studied cities led to increase in the RR of myocardial infarction, cardiovascular diseases, and obstructive pulmonary disease by $0.4 \%, 0.2 \%$, and $0.4 \%$, respectively, in 2011 . Higher RR value can depict mismanagement in urban air quality. The lower level of $\mathrm{RR}$ value might be achieved if some control strategies for reducing $\mathrm{NO}_{2}$ emission were used.
\end{abstract}

Keywords:Nitrogen Dioxide; Epidemiology; Iran

\section{Background}

During last two decades, epidemiologic studies throughout the world have evaluated the effect of air pollutionon human being health and related mortality, which showed increase in mortality due to air pollution $(1,2)$. Common air pollutants in the list of "National Ambient Air Quality Standards" include carbon monoxide (CO), ozone $\left(\mathrm{O}_{3}\right), \mathrm{PM}_{2.5}, \mathrm{PM}_{10}, \mathrm{SO}_{2}$, nitrogen dioxide $\left(\mathrm{NO}_{2}\right)$, and lead $(\mathrm{Pb})(3)$. Every human being inhales an average of $10 \mathrm{~m}^{3}$ air per day; therefore, assessment of inhaled air effects on health is a vital issue. Predictive models of concentration are classified into deterministic and statistical models. Deterministic models of air pollution, which reflect base condition of turbulence in atmosphere, are applicable tools for modeling gas pollutants and par- ticles; however, their results are always associated with substantial errors. This could be due to partial and brief description of atmosphere-complicated processes in the models. Many factors contribute to such errors among which uncertainty due to intrinsic variability of atmosphere is the most important one. Moreover, the focus of such models is based on the assumption that pollutants are dispersed in a homogenous condition, although practically the earth could be an effective factor in imbalance turbulence in a vertical pathway. In addition, input of the above mentioned models (mainly Gaussian) are frequently based on a simple programming, which assumes turbulence in classes stability atmosphere, while each class includes a wide range of atmospheric stability

Copyright (C) 2014, Ahvaz Jundishapur University of Medical Sciences. This is an open-access article distributed under the terms of the Creative Commons Attribution-NonCommercial 4.0 International License (http://creativecommons.org/licenses/by-nc/4.0/) which permits copy and redistribute the material just in noncommercial usages, provided the original work is properly cited. 
condition and depends on the place where it is evaluated (4). By utilizing available meteorological and pollution data, and analyzing their statistical correlation, statistical methods are simpler methods for predicting pollutants concentration and their applicability as well as usefulness has been demonstrated by studying short-term predictions of air pollutants using such methods $(5,6)$. Determination models of health consequences are mostly epidemiologic-statistical, integrating air quality data in concentration intervals with epidemiologic parameters such as relative risk (RR), update base, and attributable fraction, and presenting the result as death toll or mortality (1). Among seven different nitrogen oxides, NO and $\mathrm{NO}_{2}$ pose health consequences in human being. $\mathrm{NO}_{2}$ is considered a greenhouse gas that contributes to global warming. $\mathrm{NO}_{2}$ is a reddish-orange to brown gas with boiling point at $21.2^{\circ} \mathrm{C}$ and low partial pressure, which ensure its gas state. It is a corrosive, strong oxidant and a physiologic stimulant of lower respiratory tract with toxicity much more than that of $\mathrm{NO} . \mathrm{NO}_{2}$ is initially formed as NO by combination of azote and oxygen during combustion at an elevated temperature, especially in internal combustion engines and when exhausted, it is rapidly converted to $\mathrm{NO}_{2}$ (7). The main anthropologic sources of the gas include car's tailpipe, fossil fuels, power stations, industrial boilers, incinerate, and home heating systems. In urban areas, the main source of $\mathrm{NO}_{2}$ is intra-urban transport system. The concentration of $\mathrm{NO}_{2}$ changes from day to night. Air quality guidance level for $\mathrm{NO}_{2}$ is an annual average of $40 \mu \mathrm{g} / \mathrm{m}^{3}$. Some of its health impacts include increase in Met-hemoglobin (Met-Hb), enzyme activity inhibition, respiratory tract effects, general pathologic effects, and systemic effects (7). In similar work, Goudarzi et al. studied the association between chronic obstructive pulmonary disease (COPD) and $\mathrm{NO}_{2}$ levels in the Ahvaz in 2009 (8). in addition, Goudarzi et al . studied the association between COPD and $\mathrm{NO}_{2}$ levels in the Tehran in 2007 and 2011 (9, 10). Zalaghi et al. studied the association between COPD and $\mathrm{NO}_{2}$ levels in the Ahvaz, Bushehr, and Kermanshah in 2010 (11). Furthermore, health effect of air pollution in terms of $\mathrm{NO}_{2}$, ozone, and particulate matter in most of megacities, particularly Ahvaz, was reported. Health Impact Assessment software (AirQ 2.2.3, developed by the WHO European Centre for Environment Health, Bilthoven Division) was proved to be a valid and reliable tool to estimate the potential short-term effects of air pollution; AirQ predicts health endpoints attributed to criteria pollutants, and allows the examination of various scenarios in which emission rates of pollutants vary (12).

\section{Objectives}

The present study aimed at estimating and comparing epidemiologic indices attributed to the pollutant $\mathrm{NO}_{2}$ in the urban air of southwest cities of Iran, namely, Ahvaz, Kermanshah, and Bushehr in 2011.

\section{Materials and Methods}

In the present study, data relevant to the air-pollutant $\mathrm{NO}_{2}$ in 2011 were obtained from the Iranian Department of Environment as a Microsoft Excel file format. Since all air pollution measurement stations were lacking temperature sensors, 24-hour and daily air pressure and temperature data were collected from meteorological organizations of the studied cities. $\mathrm{NO}_{2}$ concentration was expressed in volume/volume percent (v/v), which was subsequently converted to mass/volume percent $(\mathrm{m} / \mathrm{v})$ using following calculations $(13,14)$ :

Formula (1): $\mathrm{B} 1=273.15+\mathrm{A} 1$

Formula (2): D1 $=(1013.25 \times \mathrm{e}[-(0.0342 \times \mathrm{C} 1) / \mathrm{B} 1])$

Formula (3): $\mathrm{E} 1=\mathrm{D} 1 / 1013.25$

Formula (3): G1 $=[(273.15 \times \mathrm{E} 1) \times(2.05 \times \mathrm{F} 1)] / \mathrm{B} 1$

Where A is temperature $\left({ }^{\circ} \mathrm{C}\right), \mathrm{B}$ is temperature (kelvin), $\mathrm{C}$ is pressure (mbar), D is pressure (atm), $\mathrm{E}$ is ratio $\mathrm{P} / \mathrm{PO}, \mathrm{G}$ is concentration $\mathrm{NO}_{2}(\mathrm{ppb})$, and $\mathrm{F}$ is concentration $\mathrm{NO}_{2}$ $\left(\mu \mathrm{g} / \mathrm{m}^{3}\right)(8,9,12)$. Primary processing including eliminating, sheet classifications of pollutant, and temporal homogenizing for mean estimation, secondary processing including code writing, mean calculation, and condition correction, primary filtering, secondary filtering, and Finally, using following equations, RR and attributable fraction of the pollutant $\mathrm{NO}_{2}$ was obtained in three studied cities. Thereafter, 24-hour means were calculated for $\mathrm{NO}_{2}$ pollutant. We estimated the health impact that was attributable to the exposure of air pollution on the target population using AirQ model, which estimates the impacts of specific air pollutants on a resident population in a certain area and period. Attributable proportion (AP) may be obtained by the following equation (15):

$$
\mathrm{AP}=\operatorname{SUM}([\operatorname{RR}(\mathrm{c})-1] \mathrm{P}(\mathrm{c})) \mathrm{z} / \mathrm{SUM}[\mathrm{RR}(\mathrm{c}) \mathrm{P}(\mathrm{c})]
$$

where $R R(c)$ is RR of health implications in the group $c$ or any group of interest, and $\mathrm{P}(\mathrm{c})$ is population proportion of the group c or any group of interest. RR of selected health implications is obtained using response-exposure functions (15)

RR = Probability of event when exposed/Probability of event when non-exposed

\subsection{Study Regions}

Ahvaz, the capital of Khouzestan Province, Iran, with an area of $8,152 \mathrm{~km}^{2}$, lies on the geographical coordinates of $30^{\circ} 45^{\prime}$ to $32^{\circ} \mathrm{N}, 48^{\circ}$ to $49^{\circ} 29^{\prime} \mathrm{E}$, southwest of Iran, with height of $22.5 \mathrm{~m}$ above sea level (16). Its climate is hot and humid. Kermanshah, the capital of Kermanshah Province, Iran, lies on the geographical coordinates of $34^{\circ} \mathrm{N}$, $47^{\circ} 4^{\prime} \mathrm{E}$ in the middle of the western part of Iran, whose climate is semiarid and mountainous temperate (17). Kermanshah's height is $1200 \mathrm{~m}$ above sea level. Bushehr is the capital of Bushehr Province, Iran, with coordinates of $28^{\circ} 95^{\prime} 76^{\prime \prime} \mathrm{N}, 50^{\circ} 83^{\prime} 71^{\prime \prime} \mathrm{E}$ and with an area of around 1441 $\mathrm{km}^{2}$ (18) (Figure 1). 


\section{Results}

Table 2 shows that in summer, winter, and the whole year 2011, Kermanshah and Bushehr had on average the maximum and minimum $\mathrm{NO}_{2}$ concentrations, respectively. In addition, according to the results, concentration of the pollutant $\mathrm{NO}_{2}$ in 2011 was more in winter than in summer in any of the three studied areas. The indices of $\mathrm{RR}$, attributable percentage, and attributable cases of $\mathrm{NO}_{2}$ for myocardial infarction (MI) with baseline incidence of 132 were calculated (Table 3). According to calculations, RR in the three studied cities for acute MI was estimated 1.0036. In addition, accumulative number of cases attributed to exposure with $\mathrm{NO}_{2}$ in the studied cities was maximum (21 cases) in Kermanshah and minimum (one case) in Bushehr. RR attributed to $\mathrm{NO}_{2}$ for COPD was estimated 1.0038 and the accumulative numbers attributed to COPD were eight and 19 in Kermanshah and Bushehr, respectively. Therefore, Kermanshah had the maximum cases of COPD among the three studied areas. Studied implications due to $\mathrm{NO}_{2}$ for calculated RR in study areas (Ahvaz, Bushehr, and Kermanshah). Figures 2-4 show health implications due to $\mathrm{NO}_{2}$ based on accumulative number of cases and epidemiologic indices. $\mathrm{RR}$ attributed to $\mathrm{NO}_{2}$ for mortality due to cardiovascular diseases (CVD) was estimated at 1.002 at intermediate level. In addition, accumulative number of death due to CVD attributed to exposure to $\mathrm{NO}_{2}$ in the studied cities was maximum (44 cases) in Kermanshah. Figures 2 and 3 illustrate that despite the estimated RR, health impacts of $\mathrm{NO}_{2}$ in concentrations $<20 \mu \mathrm{g} / \mathrm{m}^{3}$ was zero due to lack of public exposure to such concentration. In other words, there was no day with concentration $<20 \mu \mathrm{g} / \mathrm{m}^{3}$ in Ahvaz and Kermanshah. Figure 4 indicates that despite the estimated RR, health impacts of $\mathrm{NO}_{2}$ in concentrations $<10 \mu \mathrm{g} / \mathrm{m}^{3}$

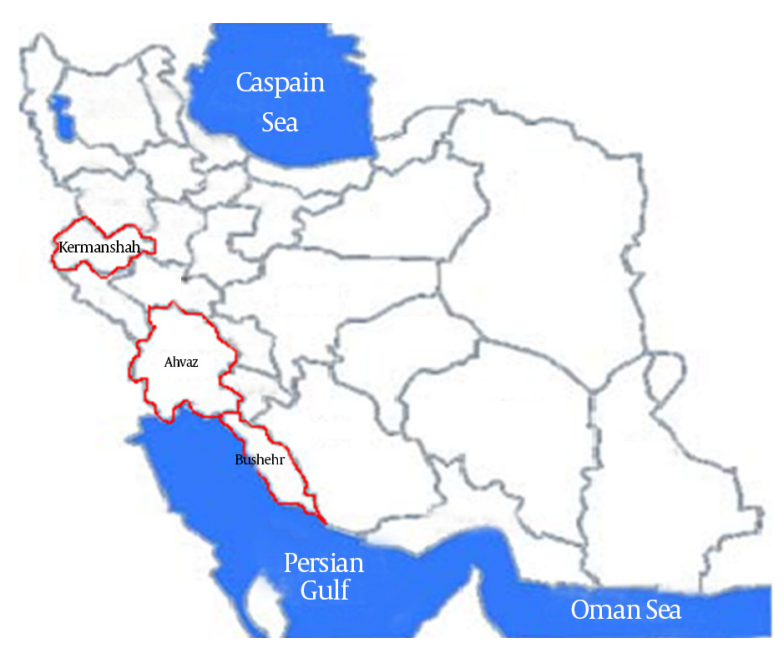

Figure 1. Study Areas Map (Ahvaz, Bushehr,Kermanshah) was zero due to lack of public exposure to such concentration. In other words, there was no day with concentration $<10 \mu \mathrm{g} / \mathrm{m}^{3}$ in Bushehr.

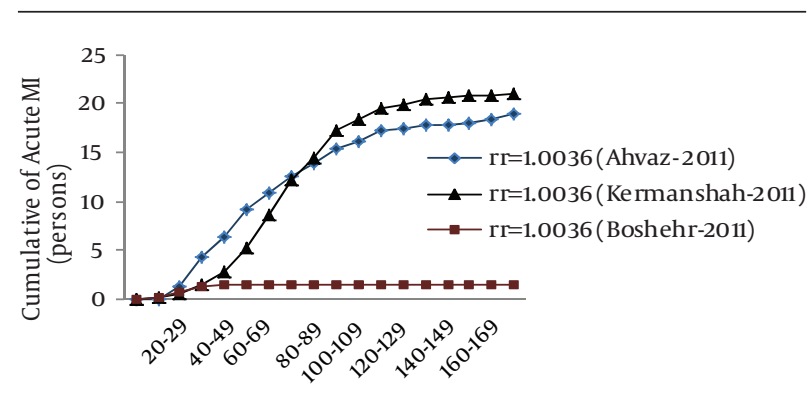

No2 concentration(microgram/cubic meter)

Figure 2. Accumulative Number of Cases of Myocardial Infarction due to Nitrogen Dioxidein Concentration Intervals in Ahvaz, Bushehr, and Kermanshah Cities in 2011

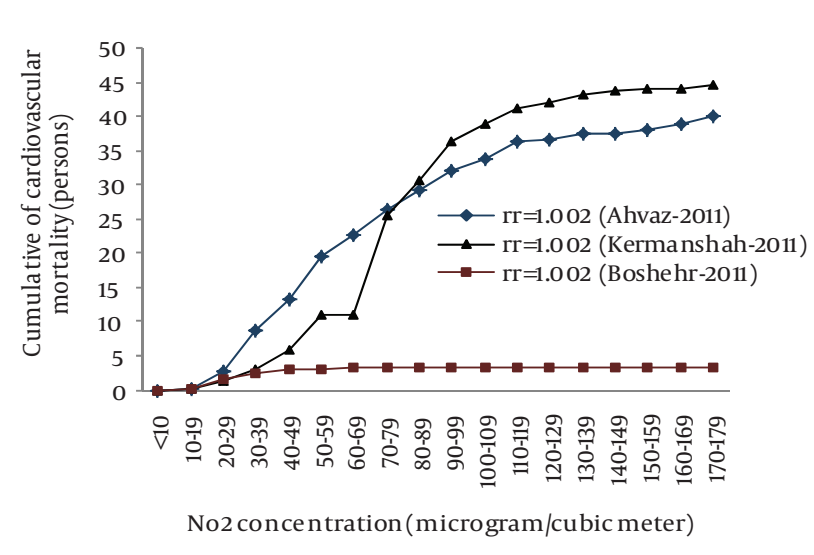

Figure 3. Accumulative Number of Cases of Cardiovascular Diseases Due to Nitrogen Dioxidein Concentration Intervals in Ahvaz, Bushehr, and Kermanshah Cities in 2011

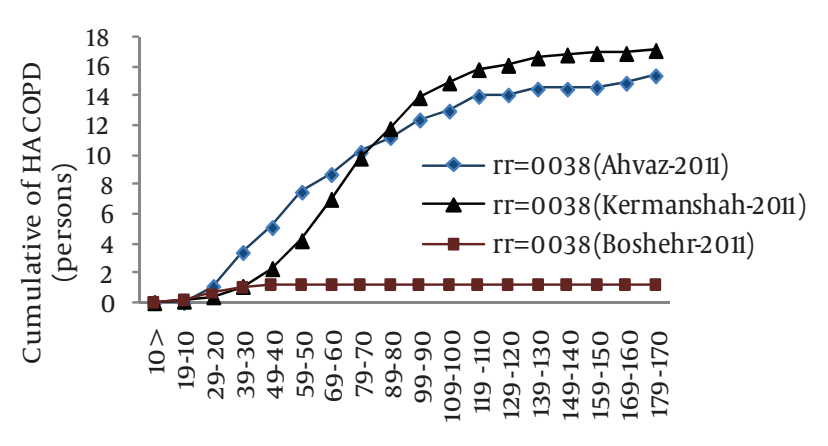

NO2 concentration (microgram/cubic meter)

Figure 4. Accumulative Number of Cases of Chronic Obstructive Pulmonary Disease Due to Nitrogen Dioxidein Concentration Intervals in Ahvaz, Bushehr, and Kermanshah Cities in 2011 
Zallaghi E et al.

\begin{tabular}{|c|c|c|c|c|c|c|}
\hline $\mathrm{T},{ }^{\circ} \mathrm{C}$ & $\mathrm{T}$, kelvin & P,mbar & $\mathbf{P}$ & $\mathbf{P} / \mathbf{P O}$ & $\mathrm{NO}_{2}, \mathrm{ppb}$ & $\mathrm{NO}_{2}, \mu \mathrm{g} / \mathbf{m}^{3}$ \\
\hline 17 & 290.15 & 1017 & 898.7855 & 0.887032 & 19.2 & 32.868 \\
\hline 18 & 291.15 & 1013 & 899.5782 & 0.887815 & 33.8 & 57.713 \\
\hline 20 & 293.15 & 1011 & 900.5189 & 0.888743 & 40 & 67.905 \\
\hline 20 & 293.15 & 1013 & 900.3088 & 0.888536 & 32.4 & 54.99 \\
\hline 21 & 294.15 & 1010 & 900.9848 & 0.889203 & 44 & 74.48 \\
\hline 25 & 298.15 & 1005 & 902.9231 & 0.891116 & 15.9 & 26.61 \\
\hline 20 & 293.15 & 1009 & 900.729 & 0.88895 & 19.9 & 33.791 \\
\hline 19 & 292.15 & 1014 & 899.8393 & 0.888072 & 53.3 & 90.725 \\
\hline 23 & 296.15 & 1015 & 901.1791 & 0.889395 & 42.3 & 71.134 \\
\hline 21 & 294.15 & 1012 & 900.7753 & 0.888996 & 45.2 & 76.493 \\
\hline 22 & 295.15 & 1015 & 900.8213 & 0.889041 & 20.8 & 35.083 \\
\hline 20 & 293.15 & 1015 & 900.0988 & 0.888328 & 19.6 & 33.258 \\
\hline
\end{tabular}

a Abbreviations: T, Temperature; P, Pressure; P0, Primary Pressure; and $\mathrm{NO}_{2}$, Nitrogen Dioxide.

Table 2. Nitrogen DioxideConcentration in $2011^{\text {a }}$

\begin{tabular}{lccc}
\hline & Ahvaz & Bushehr & Kermanshah \\
\hline Annual average & 51.53 & $27 / 76$ & 63.56 \\
Summer average & 37.29 & 23.48 & 56.53 \\
Winter average & 66.32 & 32.20 & 70.86 \\
Annual 98 percentile & 130.03 & 49.74 & 130.35 \\
Annual Maximum & 179.54 & 62.39 & 170.244 \\
Summer Maximum & 106.01 & 39.18 & 156.66 \\
Winter Maximum & 179.54 & 62.39 & 170.24 \\
\hline
\end{tabular}

a Values are measured in $\mu \mathrm{g} / \mathrm{m}^{3}$.

Table 3. Estimating Indices of Relative Risk, Attributable Proportion and Attributable Cases to Nitrogen Dioxidefor Acute Myocardial Infarction (Baseline Incidence, 132) (2011)

\begin{tabular}{lccc}
\hline & Relative Risk, Low & $\begin{array}{c}\text { Attributed Proportion (Estimated } \\
\text { Percentage), \% }\end{array}$ & Attributable Excess Cases, \% \\
\hline Ahvaz (2011) & 1.0036 & 1.4890 & 19 \\
Kermanshah (2011) & 1.0036 & 1.8936 & 21.1 \\
Bushehr (2011) & 1.0036 & 0.6419 & 1.5 \\
Ahvaz (2011) & 1.0038 & 1.5704 & 15.4 \\
Kermanshah (2011) & 1.0038 & 1.9967 & 17.1 \\
Bushehr (2011) & 1.0038 & 0.6773 & 1.2 \\
\hline
\end{tabular}

Table 4. Estimating Indices of Relative risk, Attributable Fraction and Attributable Cases to Nitrogen Dioxidefor Deaths due to Cardiovascular Diseases (Baseline Incidence of 497) (2011)

\begin{tabular}{lccc}
\hline INDEX Estimation & Relative Risk, Medium & $\begin{array}{c}\text { Attributed Proportion (Estimated } \\
\text { Percentage), }\end{array}$ & Attributable Excess Cases, \% \\
\hline Ahvaz & 1.002 & 0.8327 & 40.1 \\
Kermanshah & 1.002 & 1.0610 & 44.5 \\
Bushehr & 1.002 & 0.3576 & 3.2 \\
\hline
\end{tabular}

\section{Discussion}

According to the results, the accumulative number of MI attributed to exposure with $\mathrm{NO}_{2}$ in 2011 was 19 (10 cases more than in 2010). About $56 \%$ of MI had occurred in days with concentration $<70 \mu \mathrm{g} / \mathrm{m}^{3}$. On the other hand, $80 \%$ of the cases had occurred in days with concentration of $\mathrm{NO}_{2}<100 \mu \mathrm{g} / \mathrm{m}^{3}$. Regarding intermediate level of RR, the 
accumulative number of CVD due to exposure with $\mathrm{NO}_{2}$ was 40 (21 more than in 2010 ) in which $66 \%$ were related to concentration $<80 \mu \mathrm{g} / \mathrm{m}^{3}$. Low values of attributable percentage of COPD indicate low RR at low level (5\%); hence, the numbers of the cases in accumulative central level was estimated at 15 (18 cases more than in 2010). The indices of RR, attributable percentage, and attributable cases to $\mathrm{NO}_{2}$ for MI with baseline incidence of 132 were calculated. According to the results, accumulative number of MI attributed to exposure to $\mathrm{NO}_{2}$ in 2011 was 21 . Moreover, $41 \%$ of MI cases had occurred in days with concentration $<70$ $\mu \mathrm{g} / \mathrm{m}^{3}$. On the other hand, $82 \%$ of the cases had occurred in days with concentration of $\mathrm{NO}_{2}<100 \mu \mathrm{g} / \mathrm{m}^{3}$. Regarding intermediate level of RR, the accumulative number of CVD due to exposure to $\mathrm{NO}_{2}$ was 44 in 2011, in which $57 \%$ were related to concentration $<80 \mu \mathrm{g} / \mathrm{m}^{3}$. Accumulative number of COPD attributed to $\mathrm{NO}_{2}$ was estimated at 17. Based on the results, total cumulative number of MI attributed to exposure with $\mathrm{NO}_{2}$ was two in Bushehr in 2011 and 45\% of MI cases had occurred in days with concentration < $80 \mu \mathrm{g} / \mathrm{m}^{3}$. Accumulative number of CVD cases, regarding intermediate level of RR due to exposure with $\mathrm{NO}_{2}$ was three in 2011, in which $45 \%$ were related to concentration $<30 \mu \mathrm{g} / \mathrm{m}^{3}$. Moreover, Accumulative number of COPD attributed to $\mathrm{NO}_{2}$ was only one in 2011 .

Among the three study areas (Ahvaz, Bushehr, and Kermanshah cities), maximum and minimum annual averages of $\mathrm{NO}_{2}$ concentration were reported from Kermanshah $\left(63.58 \mu \mathrm{g} / \mathrm{m}^{3}\right)$ and Bushehr $\left(27.76 \mu \mathrm{g} / \mathrm{m}^{3}\right)$, respectively. The observed increased $\mathrm{NO}_{2}$ concentration in Kermanshah might be due to increase in home heating systems, and more burning fossil fuels, and topographical conditions of the region, which led to more stability of the pollutants in atmosphere in comparison with Ahvaz and Bushehr. The obtained results in Toronto, Canada, showed that the number of referrals to hospitals due to COPD was 7.72 cases of which $40.4 \%$ were due to exposure with $\mathrm{NO}_{2}$ (19). Goudarzi utilizes AirQ model for estimating health impacts of $\mathrm{NO}_{2}$ in Tehran, Iran, in 2007. According to the results, about $2.18 \%$ of total deaths due to CVD, $3.8 \%$ of MI, and $4.06 \%$ of hospital referrals due to COPD were attributed to concentrations $>40 \mu \mathrm{g} / \mathrm{m}^{3}(10)$. Goudarzi et al. attributed about $0.38 \%$ of total deaths due to CVD, $0.69 \%$ of MI, and $0.73 \%$ of hospital referrals due to COPD to concentrations $>20 \mu \mathrm{g} / \mathrm{m}^{3}(8,9)$. In addition, about $0.83 \%$ of deaths due to CVD, $1.48 \%$ of MI, and $1.57 \%$ of hospital referrals due to COPD were attributed to concentrations $>20 \mu \mathrm{g} \cdot \mathrm{m}^{-3}$. Comparing the results in Ahvaz, Tehran, and Toronto, suggests that the more percentage regarding death of the two implications in Ahvaz may be related to higher average of $\mathrm{NO}_{2}$ and/or days with higher concentrations in comparison to 2010. In 2011, the maximum number of observed death cases attributed to $\mathrm{NO}_{2}$ in Kermanshah were due to CVD (1.06\%), acute MI (1.8\%), and COPD $(1.9 \%)$ with concentration $>20 \mu \mathrm{g} / \mathrm{m}^{3}$. On the other hand, the minimum number of death cases was seen in Bushehr due to CVD (0.03\%), acute MI (0.06\%), and COPD (0.6\%) with concentration $>20 \mu \mathrm{g} / \mathrm{m}^{3}$. Every $10 \mu \mathrm{g} /$ $\mathrm{m}^{3}$ increase in the concentration of the pollutant $\mathrm{NO}_{2}$ in the cities of Ahvaz, Kermanshah, and Bushehr led to increase in the RR of MI, CVD, and COPD by $0.4 \%, 0.2 \%$, and $0.4 \%$, respectively, in 2011 .

\section{Acknowledgements}

The authors would like to thanks of Khuzestan Science and Research Branch, Islamic Azad University, Ahvaz, for their financial support.

\section{References}

1. Krzyzanowski M, Cohen A, Anderson R, W. H. O. Working Group . Quantification of health effects of exposure to air pollution. Occup Environ Med. 2002;59 (12): 791-3.

2. World Health Organization. WRFE. Air Quality Guidelines for Europe 2nd ed. Copenhagen:WHO Regional Publications; 2000

3. Air and Radiation. National Ambient Air Quality Standards (NAAQS): U.S. Environmental Protection Agency; 2012. Available from: http://www.epa.gov/air/criteria.html.

4. Pelliccioni A, Tirabassi T. Air dispersion model and neural network: A new perspective for integrated models in the simulation of complex situations. Environ modell softw. 2006;21 (4): 539-46.

5. Richard O. Gilbert . Statistical Methods for Environmental Pollution Monitoring.: Wiley; 1987.

6. Zannetti P. Air pollution modeling: theories, computational methods, and available software.New York: Springer; 1990.

7. Ghiyathoddin M. [Air pollution -sources, effectsand control].: Tehran University Press; 2006.

8. Goudarzi G, Mohammadi M, Ahmadi Angali K, Mohammadi B, Soleimani Z, Babaei A, et al. Estimation of Number of Cardiovascular Death, Myocardial Infarction and Chronic Obstructive Pulmonary Disease (COPD) from NO2 Exposure using Air Q Model in Ahvaz City During 2009. Iran J Health Environ. 2013;6 (1): 91-102.

9. Goudarzi G, Mohammadi MJ, Angali KA, Neisi AK, Babaei AA, Mohammadi B, et al. Estimation of Health Effects Attributed to NO2 Exposure Using AirQ Model. Arch Hyg Sci. 2011;1 (2).

10. Goudarzi G. Quantification of health effects of air pollution in Tehran and determining the impact of a comprehensive program to reduce air pollution in Tehran on the third axis [Dissertation]: Tehran University of Medical Sciences; 2007.

11. Zalaghi E. Survey of health Effects of Air Pollution Ahvaz, Bushehr and Kermanshah with Use of AIRQ Model [Dissertation]: Islamic Azad University, Science and Research Branch; 2010.

12. Zallaghi E, Goudarzi G, Geravandi S, Mohammadi MJ, Vosoughi Niri M, Vesyi E. Estimating the prevalence of cardiovascular and respiratory diseases due to particulate air pollutants in Tabriz air. Scientfic J Ilam University of Medi Sci. 2014;22 (1): 84-91.

13. Colls J.Air Pollution: Spon Press; 2002.

14. Stull RB. Meteorology for Scientists and Engineers: Brooks/Cole; 2000.

15. Pope CA, 3rd, Burnett RT, Thun MJ, Calle EE, Krewski D, Ito K, et al. Lung cancer, cardiopulmonary mortality, and long-term exposure to fine particulate air pollution. JAMA. 2002;287 (9): 1132-41.

16. Statistical Yearbook of Ahvaz.: Deputy of Planning and Development Ahvaz Municipality; 2012. Available from: http://planning. ahvaz.ir/.

17. Statistical Yearbook of Kermanshah. Deputy of Planning and Development of Kermanshah Province 2011. Available from: http:// www.ostan-ks.ir.

18. Statistical Yearbook of Bushehr: Deputy of Planning and Development of Bushehr; 2004. Available from: http://mpo-bs.ir/statics. php?id=157.

19. Burnett RT, Smith-Doiron M, Stieb D, Cakmak S, Brook JR. Effects of particulate and gaseous air pollution on cardiorespiratory hospitalizations. Arch Environ Health. 1999;54 (2):130-9. 